\title{
Buck converter optimization using P\&O algorithm for PV system based battery charger
}

\author{
Zainul Abidin, Adharul Muttaqin, Eka Maulana, M. Gilang Ramadhan \\ Department of Electrical Engineering, Universitas Brawijaya, Indonesia
}

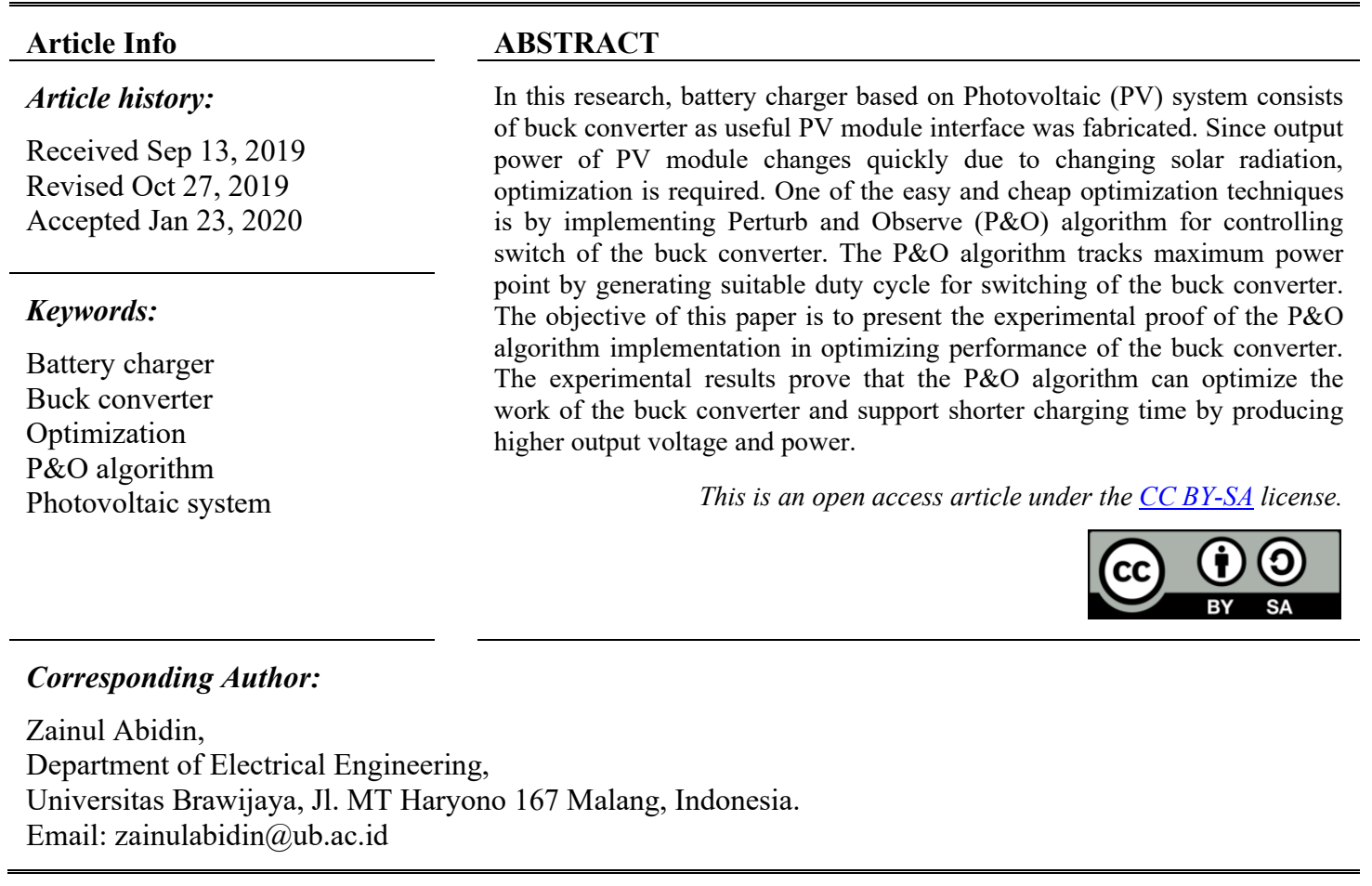

\section{INTRODUCTION}

Photovoltaic (PV) system requires DC-DC converter to adjust PV module output become suitable for load specifications [1,2]. Some DC-DC converter development is oriented towards IC fabrication [3,4]. A kind of DC-DC converter is buck converter. Development of the buck converter is also popular among researchers. For example, high conversion ratio quasi square wave buck converter is designed and presented in reference [5]. Synchronous buck converter for specific application (LED) is also evaluated by simulation [6]. Switch-inductor semi-quadratic buck converter is proposed and analyzed in reference [7]. Buck converter controlled by fuzzy logic is realized and reported in reference [8]. The buck converter is also very important part of battery charger. Battery charger based on PV system needs high efficiency. The more efficient the PV system, the shorter charging time required.

PV system efficiency is mainly affected by three factors, i.e. inverter efficiency (95-98\%) [9], PV panel efficiency which is between $8-15 \%$ (commercial PV panels) [10], and efficiency of Maximum Power Point Tracking (MPPT) algorithm which is over 98\% [11]. Improving the efficiency of the inverter and the PV panel is not easy since it depends on availability of technology. Furthermore, it may require better components and can increase drastically the installation cost. Instead, improving the tracking of the Maximum Power Point (MPP) with new or simple control algorithms is easier and cheaper. It can be done even in plants which are already used by updating their control algorithms. It would also lead to an immediate increase in PV system power generation and consequently price reduction. Since PV panels have a non-linear voltage-current characteristic with power produced is maximum in a unique point, MPPT algorithms are necessary to be implemented [12]. This point depends on irradiance conditions and on temperature of the PV panels. Both conditions are different depend on the season and change during the day. 
Moreover, solar radiation can change quickly because of changing of atmospheric conditions such as clouds and rain. Therefore, track the MPP accurately under all possible conditions is very important. As the result, maximum power is always available to be obtained [13].

In recent years, several MPPT algorithms have been published [14]. They differ in many aspects such as sensors required, complexity, cost or even efficiency. However, more expensive or more complicated algorithm is useless if with a simpler and cheaper one can obtain similar results. This is the reason why some of the proposed techniques are not implemented. Perturb and Observe (P\&O) algorithm is one of MPPT algorithms which is simple, widely used, and recently developed by many researchers [15-24]. In this paper, $\mathrm{P} \& \mathrm{O}$ algorithm implementation on buck converter of PV system for reducing battery charging time is evaluated experimentally.

\section{EXPERIMENTAL METHOD}

This section describes method of the experiment which consists of two preparations, i.e. hardware and software preparations. The hardware is designed by using commercial components which is easy to buy. The software is focused on the implementation of $\mathrm{P} \& \mathrm{O}$ algorithm.

\subsection{Hardware preparation}

Hardware requirement is based on block diagram shown in Figure 1. Generally the system needs some devices such as PV module, buck converter, current sensor and voltage divider circuit, MOSFET driver, microcontroller arduino nano and battery. Operational principle of the system is firstly the PV module receives solar radiation and converts to electricity. In order to supply load resistor or charge battery, voltage and current generated by the PV module is inputted to the buck converter which is set with a certain value of duty cycle switching. On the other side, the voltage and current generated by PV module are also sensed by current sensor and voltage divider circuit. The sensing result becomes input which is processed by arduino nano using $\mathrm{P} \& \mathrm{O}$ algorithm for controlling switch duty cycle of the buck converter. The $\mathrm{P} \& \mathrm{O}$ algorithm is used to find MPP of the PV module. The circuit realization of the system is presented in Figure 2. Performance of the buck converter will be compared with the a monolithic integrated circuit buck converter LM2596.

The buck converter is used to decrease the PV module output voltage. It was desinged for charging LiMn battery $7.4 \mathrm{~V}$. In this experiment, the buck converter mentioned in Figures 1 and 2 is realized using circuit shown in Figure 3 [8, 25-27]. Switch is realized using MOSFET and controlled by duty cycle produced by the microcontroller arduino nano. The MOSFET used in this circuit is IRFZ44N with specification of $V_{D S S}=55 \mathrm{~V}$ dan $I_{D}=49 \mathrm{~A}$, so it can be used for the circuit. The buck converter used in this experiment has some parameters, such as $V_{\text {in }}=13, V_{\text {out }}=8.6 \mathrm{~V}$, frequency $(f)=50 \mathrm{kHz}$, and $I_{\text {omax }}=1.2 \mathrm{~A}$. In buck converter design, ripple current $\left(I_{\text {ripple }}\right)$ is set in $30 \%$ of maximum current. So that, the $I_{\text {ripple }}$ is calculated as

$$
I_{\text {ripple }}=0.3 \times 1.2=0.36 A
$$

Duty cycle is calculated by comparing $V_{\text {out }}$ and $V_{\text {in }}$ as expected. Then, the duty cycle is

$$
D=\frac{V_{\text {out }}}{V_{\text {in }}}=\frac{8.6}{13}=0.66
$$

Inductor value can be determined using equation as follows.

$$
\begin{aligned}
L & =\frac{V_{\text {in }}-V_{\text {out }}}{f \times I_{\text {ripple }}} \times D \\
& =\frac{(13-8.6)}{50000 \times 13} \times 0.66 \\
& =161.3 \mu \mathrm{H} \cong 160 \mu \mathrm{H}
\end{aligned}
$$

After determining the inductor value, the capacitance can be calculated as follows.

Buck converter optimization using P\&O algorithm for PV system based battery charger... (Zainul Abidin) 


$$
\begin{aligned}
C & =\frac{V_{\text {out }}(1-D)}{8 L \times f^{2} \times \Delta V_{\text {out }}} \\
& =\frac{8.6(1-0.66)}{8 \times 161.3 \times 10^{-6} \times 50000^{2} \times 50 \times 10^{-3}} \times 0.66 \\
& =181 \mu F \cong 20 \mu F
\end{aligned}
$$

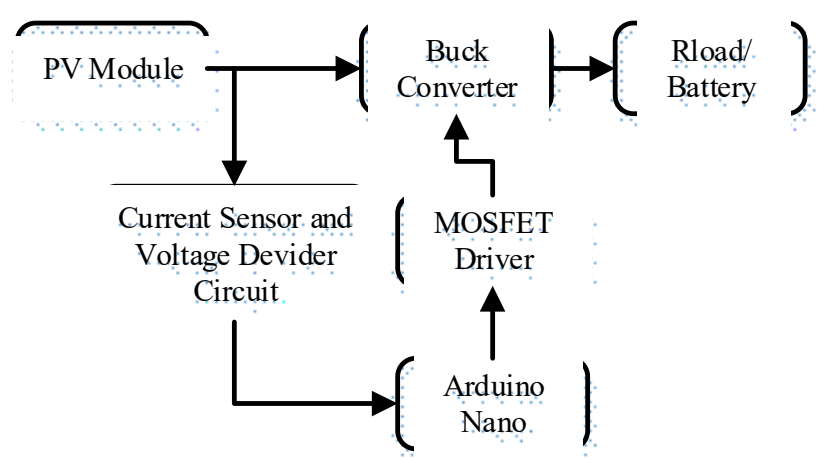

Figure 1. Block diagram of the experimental setup
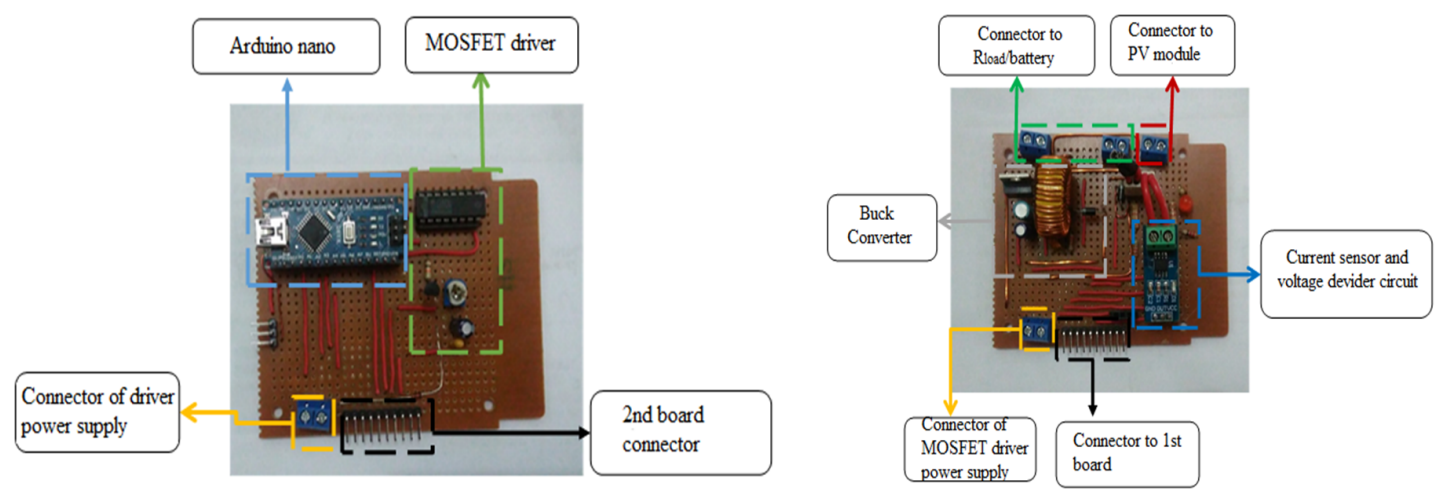

Figure 2. Circuit realization of PV system based battery charger

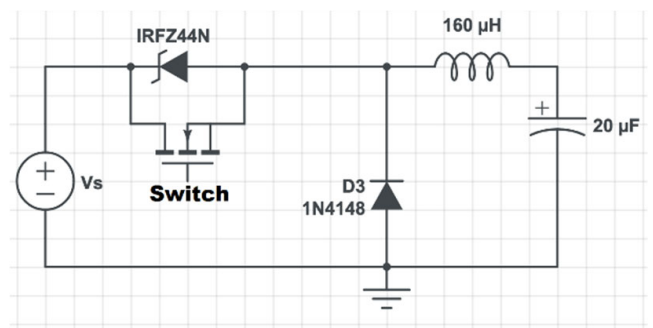

Figure 3. Buck converter circuit

\subsection{Software preparation ( $\mathrm{P} \& \mathrm{O}$ algorithm)}

As mentioned in previous sub section, arduino nano is used to implement the $\mathrm{P} \& \mathrm{O}$ algorithm. The principle of the $\mathrm{P} \& \mathrm{O}$ algorithm is illustrated in Figure 4 [15, 18, 22, 24]. After generated and processed (see 
Figure 1), the voltage $\left(V_{k}\right)$ and current $\left(I_{k}\right)$ are calculated to get output power $(P k)$. Then, the $P_{k}$ is compared to previous output power $\left(P_{k-1}\right)$ to get deviation $\left(P_{k}-P_{k-1}\right)$ The deviation of the $P_{k}$ and $P_{k-1}$ is used as condition to determine the duty cycle must be increased or decreased. If the deviation is zero, it means there is no difference between $P_{k}$ and $P_{k-1}$, then the Pk must be saved for next calculation. However, in the case of the deviation is not zero, further process and condition selection are necessary. It leads to 4 conditions, i.e.

- If $P_{k}-P_{k-1}<0$ and $V_{k}-V_{k-1}<0$, then the duty cycle must be increased and $V_{k}$ increase

- If $P_{k}-P_{k-1}<0$ and $V_{k}-V_{k-1}>0$, then the duty cycle must be decreased and $V_{k}$ decrease.

- If $P_{k}-P_{k-1}>0$ and $V_{k}-V_{k-1}>0$, then the duty cycle must be increased and $V_{k}$ increase.

- If $P_{k}-P_{k-1}>0$ and $V_{k}-V_{k-1}<0$, then the duty cycle must be decreased and $V_{k}$ decrease.

So that the output of the $\mathrm{P} \& \mathrm{O}$ algorithm is duty cycle for switching of buck converter. It changes based on the output power deviation.

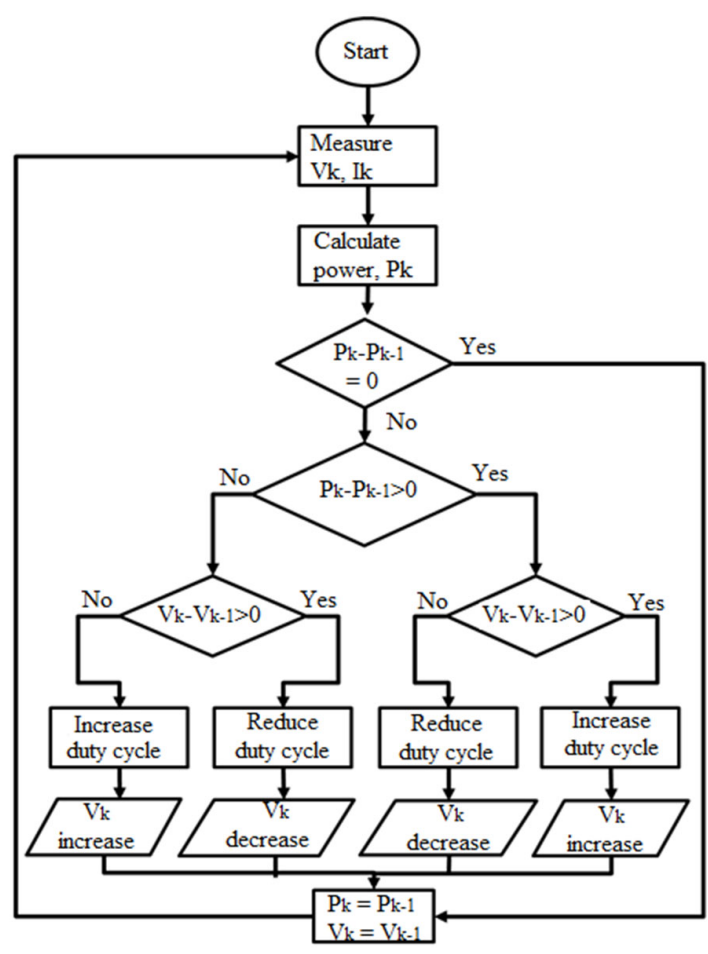

Figure 4. Flowchart of $\mathrm{P} \& \mathrm{O}$ algorithm

\section{EXPERIMENTAL RESULT}

The P\&O algorithm was implemented to the PV system. In this section, the experimental results are presented to confirm effectiveness of the $\mathrm{P} \& \mathrm{O}$ algorithm. The experimental results are presented based on output power of the PV system and battery charging performance.

\subsection{Output power of the PV system}

In this sub section, experiment based on output power is discussed in detail. The experiment block diagram is shown in Figure 5. The experiment compares the output power of the designed buck converter with $\mathrm{P} \& \mathrm{O}$ algorithm and buck converter LM2596 without $\mathrm{P} \& \mathrm{O}$ algorithm. The experimental results are shown in Figure 6. Load resistance was varied from $10 \Omega$ until $45 \Omega$. The highest output power of the one with $\mathrm{P} \& \mathrm{O}$ algorithm is 7.64 watt when the load resistance is $10 \Omega(\mathrm{V}=9.56 \mathrm{~V}$ and $\mathrm{I}=0.799 \mathrm{~A})$. The one without $\mathrm{P} \& \mathrm{O}$ algorithm reaches the highest ouput power of 7.22 watt. The output power decreases along with bigger load resistance. The one with $\mathrm{P} \& \mathrm{O}$ algorithm has higher output power in every load resistances. It means the $\mathrm{P} \& \mathrm{O}$ algorithm works well even it looks unstable in maintaining the output power. The output power can not be stable because voltage source used by the MOSFET driver was taken from PV module. So, when the output power decreases, so does the voltage in gate of the MOSFET. This condition affects to the P\&O algorithm during finding the maximum power point.

Buck converter optimization using P\&O algorithm for PV system based battery charger... (Zainul Abidin) 


\subsection{Battery charging performance}

In this sub section, certain time intervals are decided to confirm charging time performance. The experiment block diagram is shown in Figure 7. Charging were done in outdoor by 15 minutes and 45 minutes for both the buck converter with $\mathrm{P} \& \mathrm{O}$ algorithm and the LM2596 without P\&O algorithm. The more power saved in battery the shorter charging time required. Batteries used in this experiment are with voltage of 7.8 V. Experiment were done for 6 times during $8 \mathrm{AM}-1$ PM. Experiment result is shown in Tables 1 and 2. The 15 minutes experiment results show the highest charging result of the one without $\mathrm{P} \& \mathrm{O}$ algorithm and with $\mathrm{P} \& \mathrm{O}$ algorithm are are $0.04 \mathrm{~V}$ and 0.29 , respectively. Moreover, the 45 minutes experiment results show the highest charging result of the one without $\mathrm{P} \& \mathrm{O}$ algorithm and with $\mathrm{P} \& \mathrm{O}$ algorithm are $0.13 \mathrm{~V}$ and $0.66 \mathrm{~V}$, respectively. Both experiment results prove that the $\mathrm{P} \& \mathrm{O}$ algorithm can optimize the work of buck converter and support shorter charging time.

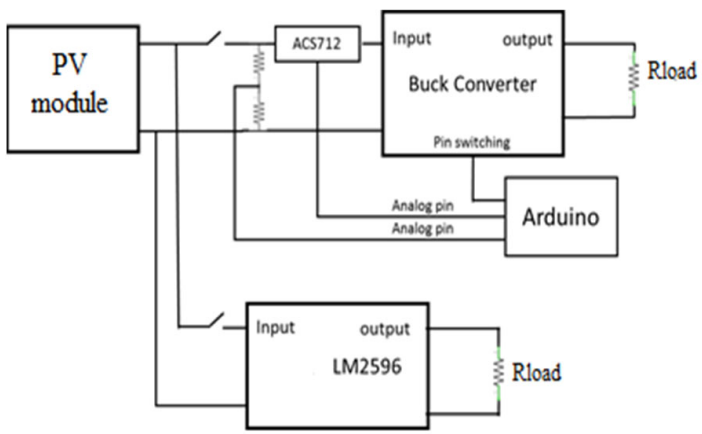

Figure 5. Block diagram of output power based experiment

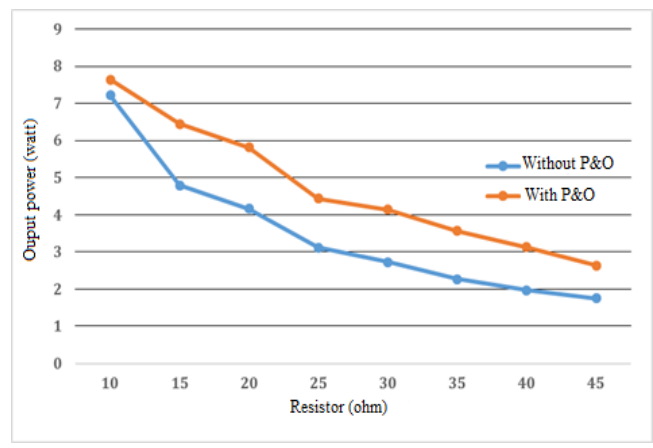

Figure 6. Experimental result of output power

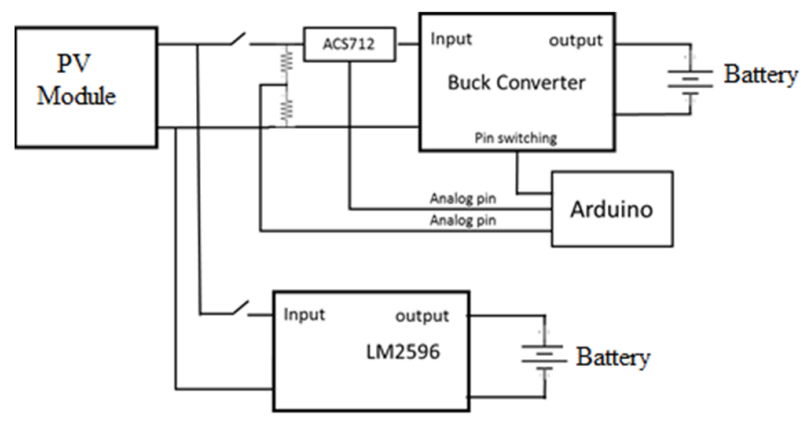

Figure 7. Experimental result of output power

Table 1. Experimental results for 15 minutes charging

\begin{tabular}{|c|c|c|c|c|c|c|c|c|c|c|c|c|}
\hline \multirow[b]{2}{*}{ Exp. no } & \multicolumn{6}{|c|}{ Without P\&O } & \multicolumn{6}{|c|}{ With P\&O } \\
\hline & 1 & 2 & 3 & 4 & 5 & 6 & 1 & 2 & 3 & 4 & 5 & 6 \\
\hline $\mathrm{V}_{\text {start }}(\mathrm{V})$ & 7.8 & 7.83 & 7.83 & 7.79 & 7.82 & 7.82 & 7.78 & 7.81 & 7.81 & 7.73 & 7.78 & 7.79 \\
\hline $\mathrm{V}_{\text {stop }}(\mathrm{V})$ & 7.8 & 7.83 & 7.86 & 7.8 & 7.86 & 7.83 & 7.97 & 7.86 & 7.96 & 8.02 & 7.97 & 8.06 \\
\hline Charging result $(\mathrm{V})$ & 0 & 0 & 0.03 & 0.01 & 0.04 & 0.01 & 0.19 & 0.05 & 0.15 & 0.29 & 0.19 & 0.27 \\
\hline
\end{tabular}

Table 2. Experimental results for 45 minutes charging

\begin{tabular}{lllllllllllll}
\hline & \multicolumn{1}{c}{ Without P\&O } & \multicolumn{1}{c}{ With P\&O } \\
Exp. no & 1 & 2 & 3 & 4 & 5 & 6 & 1 & 2 & 3 & 4 & 5 & 6 \\
\hline Vstart $(\mathrm{V})$ & 7.8 & 7.83 & 7.83 & 7.79 & 7.82 & 7.82 & 7.78 & 7.81 & 7.81 & 7.73 & 7.78 & 7.79 \\
Vstop $(\mathrm{V})$ & 7.83 & 7.96 & 7.89 & 7.83 & 7.89 & 7.85 & 8.32 & 8.12 & 8.27 & 8.39 & 8.1 & 8.4 \\
Charging result $(\mathrm{V})$ & 0.03 & 0.13 & 0.06 & 0.04 & 0.07 & 0.03 & 0.54 & 0.31 & 0.46 & 0.66 & 0.32 & 0.61 \\
\hline
\end{tabular}




\section{CONCLUSION}

In this paper, the $\mathrm{P} \& \mathrm{O}$ algorithm applied for buck converter of PV system based battery charger has been presented. The $\mathrm{P} \& \mathrm{O}$ algorithm can control duty cycle for switching of buck converter. According output power and charging time, the buck converter with $\mathrm{P} \& \mathrm{O}$ algorithm has higher output power and shorter charging time than the one without $\mathrm{P} \& \mathrm{O}$ algorithm. It proves that the buck converter can be optimized by using P\&O algorithm. Since output power is not stable, in the future, advanced algorithm that can produce more stable output power will be developed. In order to confirm performance of the designed buck converter, future research will also be conducted with two identical PV modules and precisely same setup for the designed buck converter and the fabricated one.

\section{ACKNOWLEDGEMENTS}

This work is supported by Lembaga Penelitian dan Pengabdian Masyarakat Universitas Brawijaya (LPPM-UB) through Hibah Peneliti Pemula (Award No. 696.53/UN10.C10/PN/2019).

\section{REFERENCES}

[1] M. S. Malik, et al., "Evaluation of a Single Inductor based Single-Input Dual-Output Buck Converter for DC Microgrid Applications", in 2018 IEEE 7th World Conference on Photovoltaic Energy Conversion (WCPEC), 2018, pp. 613-617.

[2] R. K. Subroto, et al., "Voltage Regulation of Boost Converter Using Observer Based Sliding Mode Controller", TELKOMNIKA (Telecommunication, Computing, Electronics and Control), vol 16, no. 6, pp. 2896-2903, 2018.

[3] J.J. Chen, et al., "A New Single-Inductor Triple-Output Buck Converter Using CMOS Technology," in The 2010 International Power Electronics Conference, 2010, pp. 82-85.

[4] V. Michal, "Inductor Current Zero-Crossing Detector and CCM/DCM Boundary Detector for Integrated HighCurrent Switched-Mode DC-DC Converters", IEEE Transaction on Power Electronics, vol 29, no. 10, pp. $5384-$ 5391, 2013.

[5] Y. Naeimi and A. Huang, "Design and Optimization of High Conversion Ratio Quasi Square Wave Buck Converters", in 2017 IEEE 5th Workshop on Wide Bandgap Power Devices and Applications (WiPDA), 2017, pp. 148-152.

[6] C. Deekshitha and K. L. Shenoy, "Design and Simulation of Synchronous Buck Converter For LED Application", in 2017 2nd IEEE International Conference On Recent Trends In Electronics Information \& Communication Technology, 2017, pp. 142-146.

[7] P. V. Anushka, et al., "Switched-Inductor Semi-Quadratic Buck Converter", in 2017 IEEE International Conference on Technological Advancements in Power and Energy (TAP Energy), 2017, pp. 1-6.

[8] K. Swathy, et al., "Design and Hardware Implementation of Closed Loop Buck Converter Using Fuzzy Logic Controller", in 2nd International conference on Electronics, Communication and Aerospace Technology (ICECA 2018), 2018, pp. 175-180.

[9] "Sunny Family 2010/2011 - The Future of Solar Technology", SMA product catalogue, 2010.

[10] "Trends in photovoltaic applications. Survey report of selected IEA countries between 1992 and 2009," International Energy Agency, Report IEA-PVPS Task 1 T1-19:2010, 2010.

[11] L. Piegari and R. Rizzo, "Adaptive Perturb and Observe Algorithm for Photovoltaic Maximum Power Point Tracking", IET Renewable Power Generation, vol 4, no. 4, pp. 317-328, 2010.

[12] N. Femia, et al., "Optimizing Sampling Rate of P\&O MPPT Technique", in 2004 IEEE 35th Annual Power Electronics Specialists Conference, 2004, pp. 1945 - 1949.

[13] M. Chakkarapani, et al., "On the Issues in MPPT Implementation for PV Systems", in 21st Century Energy Needs Materials, Systems and Applications (ICTFCEN), 2016, pp. 1-6.

[14] T. Esram and P. L. Chapman, "Comparison of Photovoltaic Array Maximum Power Point Tracking Techniques", IEEE Transactions on Energy Conversion, vol 22, no. 2, pp. 439-449, 2007.

[15] J. Ahmed and Z. Salam, "An Improved Perturb and Observe (P\&O) Maximum Power Point Tracking (MPPT) Algorithm for Higher Efficiency, " Applied Energy, vol 150, pp. 97-108, 2015.

[16] M. Kamran, et al., "Implementation of Improved Perturb \& Observe MPPT Technique with Confined Search Space for Standalone Photovoltaic System," Journal of King Saud University - Engineering Sciences, in press, 2018.

[17] R. Alik and A. Jusoh, "An Enhanced P\&O Checking Algorithm MPPT for High Tracking Efficiency of Partially Shaded PV Module," Solar Energy, vol 163, pp. 570-580, 2018.

[18] C. W. Tan, et al., "Analysis of Perturb and Observe Maximum Power Point Tracking Algorithm for Photovoltaic Applications," in 2nd IEEE International Conference on Power and Energy (PECon 08). 2008, pp. 237-242.

[19] M. A. Elgendy, et al., "Assessment of Perturb and Observe MPPT Algorithm Implementation Techniques for PV Pumping Applications," IEEE Transactions on Sustainable Energy, vol 3, no. 1, pp. 21-33, 2012.

[20] J. J. Nedumgatt, et al., "Perturb and Observe MPPT Algorithm for Solar PV Systems-modeling and Simulation," in Annual IEEE India Conference, 2011, pp. 1-6.

[21] A. Ali, et al., "Perturb and Observe Based on Fuzzy Logic Controller Maximum Power Point Tracking (MPPT)," in 3rd International Conference on Renewable Energy Research and Applications (ICRERA), 2014, pp. 406-411. 
[22] M. Killi and S. Samanta, "Modified Perturb and Observe MPPT Algorithm for Drift Avoidance in Photovoltaic Systems," IEEE Transactions on Industrial Electronics, vol 62, no. 9, pp. 5549 - 5559, 2015.

[23] M. L. Azad, et al., "P\&O Algorithm Based MPPT Technique for Solar PV System Under Different Weather Conditions, " in International Conference on circuits Power and Computing Technologies [ICCPCT], pp. 1-5, 2017.

[24] R. John, et al., "Variable Step Size Perturb and Observe MPPT Algorithm for Standalone Solar Photovoltaic System," in IEEE International Conference on Intelligent Techniques in Control, Optimization and Signal Processing (INCOS), 2017, pp. 1-6.

[25] M. Qin, et al., "Analysis and Comparison of Voltage-Mode and Current-Mode Pulse Train Control Buck Converter, " in 2009 4th IEEE Conference on Industrial Electronics and Applications, 2009, pp. 2924-2928.

[26] S Liu, et al., "Design of Intrinsically Safe Buck DC/DC Converters," in 2005 International Conference on Electrical Machines and Systems, 2005, pp. 1327-1331.

[27] C. Sharma and A. Jain, "Modeling of Buck Converter Models in MPPT using PID and FLC," TELKOMNIKA (Telecommunication, Computing, Electronics and Control), vol 13, no. 4, pp. 1270-1280, 2015.

Int J Pow Elec \& Dri Syst, Vol. 11, No. 2, June 2020 : 844 - 850 